\section{A saliência em anúncios publicitários: reflexões multimodais*}

The salience in advertising: multimodal reflexions

Jammara Oliveira Vasconcelos de SÁ (UERN) jammaravasconcelos@gmail.com

Lara Marques de OLIVEIRA (UERN)

lara_marx@hotmail.com

Lucineide Matos LOPES (SEDUC) lucineidematoslopes@gmail.com

Recebido em: 30 de out. de 2019. Aceito em: 06 de maio de 2020.

*Trabalho fruto do projeto contemplado com bolsa do PIBIC/ UERN para aluno e apresentado em Comunicação oral no I Encontro Nacional em Linguística SistêmicoFuncional. Evento realizado em Fortaleza no dia 07 de junho de 2019.
SÁ, Jammara Oliveira Vasconcelos de; OLIVEIRA, Lara Marques de; LOPES, Lucineide Matos. A saliência em anúncios publicitários: reflexões multimodais. Entrepalavras

Fortaleza, v. 10, n. esp., p. 50-65, ago. 2020. DOI: $10.22168 / 2237-6321-$ gesp1764.

Resumo: Nosso trabalho tem como objetivo discutir sobre como a saliência contribui para os efeitos de sentidos na composição do anúncio publicitário. Orientadas pelos pressupostos da pesquisa qualitativa de cunho descritivista, selecionamos 10 anúncios da internet dos quais trazemos três para ilustrar nossas reflexões na análise. No que tange ao embasamento teórico, amparamo-nos nos estudos de Kress e van Leeuwen (2006) ao defendermos que, na sociedade contemporânea, várias semioses influenciam fortemente a produção de textos multimodais nos quais o verbal e o imagético articulam-se de forma integrada. Entre os sistemas propostos por Kress e van Leeuwen (2006), focamos nosso olhar nos aspectos pertinentes à saliência nos anúncios, assumindo-a como a maneira de chamar a atenção do leitor para um segmento do texto por meio dos elementos que são dispostos para atrair a atenção do espectador em diferentes graus, realizando-se através de certos fatores, tais como: o posicionamento em primeiro ou em segundo plano, o tamanho relativo, os contrastes quanto ao tom (ou à cor), diferenças quanto à nitidez, dentre outros elementos (KRESS; VAN LEEUWEN, 2006). A partir de nossa análise, podemos 
afirmar que, na articulação dos recursos que compõem o gênero anúncio, a manipulação do tamanho das imagens e o contraste ocasionado por essa manipulação de tamanhos, o uso das cores, o tamanho e o tipo da letra representaram um forte aspecto da saliência no gênero, atuando a serviço da persuasão no anúncio e funcionando como importante recurso na divulgação dos produtos.

Palavras-chave: Anúncio publicitário. Sistemas. Saliência.

Abstract: Our work aims to discuss how the salience contributes to the effects of meanings in the composition of the advertising. Guided by the assumptions of qualitative research of descriptive nature, we selected 10 advertising internet, of which we present 3 of them to illustrate our reflections in the analysis. Regarding the theoretical basis, we rely on the studies of Kress and van Leeuwen (2006) when we argue that, in contemporary society, several semioses strongly influence the production of multimodal texts in which the verbal and the imagery articulate in an integrated manner. Among the systems proposed by Kress and van Leeuwen (2006), we focus our view on the aspects relevant to the salience in the advertising, assuming it as the way to draw the reader's attention to a segment of the text through the elements that are arranged to attract the viewer's attention to different degrees, accomplishing through certain factors such as positioning in the foreground or background, relative size, contrasts in tone (or color), differences in sharpness, among other elements (KRESS; VAN LEEUWEN, 2006). From our analysis, we can affirm that, in the articulation of the resources that compose the advertising genre, the manipulation of the size of the images and the contrast caused by this manipulation of sizes, the use of colors, the size and the font represented a strong aspect of salience in the genre, acting in the service of persuasion in the advertising and functioning as an important resource in the publishing of products.

Keywords: Advertising. Systems. Salience.

\section{Introdução}

Ao observarmos o contexto social atual, não podemos desprezar o fato de que vivemos numa sociedade em que as multissemioses articulamse nos diferentes gêneros para atender à intencionalidade comunicativa de seus interlocutores. Nesse processo, a comunicação extrapola os limites da escrita e assume variadas formas, permitindo ao enunciador utilizar inúmeras semioses para comunicar e expor seu ponto de vista.

Neste cenário, a busca por compreender melhor os aspectos envoltos na composição de sentidos dos textos, especialmente dos imagéticos, tem motivado inúmeros trabalhos que tentam dar conta de analisar esse processo.

Se direcionarmos nosso olhar para o ambiente virtual, com a propagação do hábito cada vez mais comum de consumirmos produtos e serviços por meio da internet, a necessidade de pesquisas no âmbito da linguagem que discutam temas relacionados a essa prática é indispensável no cenário brasileiro atual. Especialmente no que diz respeito ao gênero anúncio publicitário, um dos principais meios de 
v. 10 (esp) $50-65$ ago. 2020 divulgação de produtos e de serviços, o desenvolvimento de pesquisas que contribuam com um maior aprofundamento das reflexões sobre a relação entre o verbal e o imagético na composição do anúncio publicitário faz-se importante e necessário.

Reconhecendo, portanto, a pertinência das pesquisas sobre essa temática, as contribuições deste artigo foram norteadas pela seguinte questão de pesquisa: de que maneira a saliência contribui para os efeitos de sentidos na composição do gênero anúncio publicitário?

Neste sentido, os estudos de Kress e van Leeuwen (2006) sobre a Gramática do Design Visual (GDV) muito têm contribuído para os trabalhos que tencionam analisar os aspectos que extrapolam a linguagem verbal e invadem o universo das imagens e do som, servindonos de embasamento teórico.

Na busca por discutir sobre como a saliência contribui para os efeitos de sentidos na composição do gênero anúncio publicitário, este artigo organiza-se em cinco seções. Nesta primeira seção, contextualizamos a discussão que empreendemos ao longo do trabalho e, ainda, mostramos a sistematização adotada para o artigo. Na segunda seção, discutimos sobre a fundamentação teórica que adotamos, mostrando como ela serviu de base para este trabalho. Na terceira seção, mostramos nossa metodologia. Dando continuidade, na seção seguinte, apresentamos nossa análise e os resultados encontrados, com foco nos aspectos pertinentes à composição visual dos textos pelo viés da observação da saliência à luz da nossa fundamentação teórica. Por fim, chegamos às considerações finais disponibilizando ao nosso leitor, resumidamente, um arremate das reflexões empreendidas no artigo.

\section{A Linguística Sistêmico-Funcional: alicerce para a Gramática do Design Visual}

É no cerne das contribuições de Halliday (1994) e de Halliday e Matthiessen (2004) que encontramos muitos dos pressupostos da Linguística Sistêmico-Funcional (doravante LSF) e que influenciaram, fortemente, as discussões de Kress e van Leeuwen (2006) na proposição da Gramática do Design Visual (doravante GDV).

Diante disso, convém comentarmos alguns pressupostos basilares desta vertente linguística para chegarmos à proposição da gramática de Kress e van Leeuwen (2006) e, oportunamente, a uma discussão do aspecto da saliência nos anúncios. 
Segundo Motta-Roth e Heberle (2005), Halliday (1994), ao denominar sua proposta de Linguística Sistêmico-Funcional, explica esta denominação pelos seguintes motivos: a) é sistêmica por se referir à linguagem como redes de escolhas, relacionadas a variáveis de registro e de macro e microestruturas, b) é funcional por sua relação com a atividade social em andamento num dado contexto.

A LSF parte de uma concepção de linguagem como um sistema sociossemiótico que veicula diferentes significados dependendo das intenções dos interlocutores, do lugar de que se fala, da situação de interação, do contexto de cultura onde ocorre o evento discursivo, dentre outros aspectos (HALLIDAY; MATTHIESSEN, 2004).

Neste sistema sociossemiótico, a visão hallidayana da gramática evidencia o caráter dialético entre a situação (o fazer) e sua materialização no léxico, na gramática e em todos os níveis de significação da linguagem (o dizer). Nesta perspectiva de gramática, o texto é definido como a "instância de uso da linguagem viva que está desempenhando um papel em um contexto de situação" (MOTTAROTH; HEBERLE, 2005, p. 13).

Considerando que o contexto da situação compreende tudo aquilo que é relevante para a interação, ele se define pelas seguintes variáveis: campo (a natureza da prática social), relação (a natureza da conexão entre os participantes da situação) e modo (a natureza do meio de transmissão da mensagem).

Segundo Halliday (1994), neste processo de interação, o campo, a relação e o modo realizam-se através das três metafunções da linguagem que atuam, simultaneamente, nos textos. São elas: a metafunção ideacional, a metafunção interpessoal e a metafunção textual.

Para o autor, a metafunção ideacional estáligada à representação da experiência ao conteúdo ideacional presente em todos os usos da linguagem. Esta função, segundo o autor, refere-se ao reflexo da realidade da língua nos enunciados envoltos em eventos, ações, estados e outros processos da atividade humana através da relação simbólica.

A metafunção interpessoal diz respeito ao significado assumido no processo de interação social da língua como ação, possibilitando ao sujeito representar ações sobre os outros dentro da realidade social e desencadear novas ações. Já a metafunção textual contempla a estrutura e o formato do texto, possibilitando ao sujeito estruturar a experiência em textos, articulando os diferentes sistemas que envolvem a língua. 
v. 10 (esp) $50-65$ ago. 2020

É nessa articulação entre as variáveis pertinentes ao campo, à relação e ao modo, possibilitada pelas categorias que abarcam as metafunções de Halliday mencionadas acima que surge a Gramática do Design Visual de Kress e van Leeuwen (2006), como uma tentativa de analisar a comunicação enquanto atividade multissemiótica composta por elementos verbais e não verbais. Passaremos, então, à discussão de alguns dos pressupostos da GDV, considerando o fato de o nosso trabalho ter como objetivo o olhar sobre a saliência pelo viés da perspectiva teórica defendida por estes pesquisadores.

\section{A Gramática do Design Visual: algumas considerações}

A partir da concepção de comunicação como uma atividade multissemiótica na qual a multimodalidade é característica de qualquer texto, cujos sentidos são produzidos através de mais de um código semiótico, Kress e van Leeuwen (2006), principais representantes da Teoria Semiótica Social, defendem a importância de analisarmos os recursos visuais e sonoros (quando existentes) na tessitura textual. Segundo os autores, o uso desses recursos tem uma função informativa que não pode ser analisada, apenas, como "ornamental" na construção dos sentidos dos gêneros. Para eles, a linguagem visual não depende da linguagem verbal.

Diante disso, na teia das multissemioses que compõem a comunicação, a linguagem verbal e a linguagem visual não representam a mesma informação, simplesmente, elas carregam significados vinculados a cada uma dessas linguagens, sejam verbais, visuais ou sonoras.

Nesta perspectiva, com o objetivo de possibilitar estudos que abordem as relações entre as variadas formas de linguagens, verificando, a partir disso, como todos os recursos semióticos presentes em um texto constroem, de maneira articulada, significados sociais, Kress e van Leeuwen (2006) propõem a Gramática do Design Visual, proporcionando, por meio desta gramática, uma metodologia para a análise de textos multimodais.

Tendo como principal alicerce as metafunções da linguagem, apresentadas na Gramática Sistêmico-Funcional de Halliday (1994), a GDV caracteriza-se, segundo seus idealizadores, pela preocupação em analisar o modo como as imagens representam as relações entre as pessoas, os lugares e as coisas que tais imagens retratam, bem como 
o complexo conjunto de relações que podem existir entre as imagens e seus espectadores. De acordo com os postulados de Kress e van Leeuwen (2006), Petermann (2006) resume a estrutura básica da Gramática do Design Visual no quadro (1).

Quadro 1 - Estrutura básica da Gramática do Design Visual

\begin{tabular}{|l|l|}
\hline Metafunção ideacional: & $\begin{array}{l}\text { Estrutura narrativa (Ação transacional, } \\
\text { Ação não-transacional, Reação } \\
\text { Representação das experiências de mundo } \\
\text { por meio da linguagem }\end{array}$ \\
$\begin{array}{ll}\text { transacional, Reação não-transacional, } \\
\text { Processo mental, Processo verbal); } \\
\text { Estrutura conceitual (Processo } \\
\text { classificacional, Processo analítico, } \\
\text { Processo simbólico); }\end{array}$ \\
\hline $\begin{array}{l}\text { Metafuncão interpessoal: } \\
\text { Estratégias de aproximação/afastamento } \\
\text { para com o leitor }\end{array}$ & $\begin{array}{l}\text { Contato (Pedido - Interpelação ou Oferta) } \\
\text { Distância Social (social, pessoal, íntimo) } \\
\text { Atitude (objetividade ou subjetividade) } \\
\text { Modalidade (valor de verdade); }\end{array}$ \\
\hline Metafunção textual: & $\begin{array}{l}\text { Valor de Informação (Ideal - Real, Dado } \\
\text { - Novo) } \\
\text { Sodos de organização do texto. } \\
\text { defincia (elementos mais salientes que caminho de leitura) } \\
\text { Moldura (o modo como os elementos } \\
\text { estão conectados na imagem). }\end{array}$ \\
\hline
\end{tabular}

Fonte: Petermann (2006, p. 3).

Diante dos elementos que compõem o quadro resumitivo 1, é necessário salientar que nos deteremos nos aspectos pertinentes à metafunção textual, especificamente nos elementos envoltos na saliência presente nos anúncios publicitários, visto que uma discussão que contemple os elementos relativos às metafunções ideacional e interpessoal foge ao escopo deste artigo e aponta para a necessidade de estudos futuros sobre essas questões.

A composição visual na GDV

Uma das preocupações subjacentes ao estudo da multimodalidade discursiva diz respeito à configuração das produções de sentido a partir da linguagem visual, que muitas vezes está intimamente relacionada aos elementos verbais. Assim, os teóricos afirmam seu posicionamento integrativo no que diz respeito à produção de sentidos dos textos. Nesta perspectiva, a composição textual multimodal está relacionada a três sistemas inter-relacionados. São eles: o valor informativo, o framing e a saliência. 
v. 10 (esp) $50-65$ ago. 2020

Visando proporcionar apenas um panorama de diferenciação destes sistemas para o nosso leitor, apresentaremos sucintamente alguns aspectos importantes quanto ao estudo do valor informativo e do framing conforme a GDV. Esta decisão explica-se pelo fato de que nosso artigo tem como escopo, apenas, o tratamento da saliência nos anúncios publicitários.

No que tange ao valor informativo das imagens, esse sistema diz respeito aos valores conferidos de acordo com a posição dos participantes, dos sintagmas e dos telespectadores. Dessa maneira, Kress e van Leeuwen (2006) sugerem que:

a localização dos elementos (dos participantes e dos sintagmas que os conectam uns aos outros e ao espectador) lhes confere valores informativos específicos relacionados às várias "zonas" da imagem: esquerda e direita, parte superior e parte inferior, centro e margem (KRESS; VAN LEEUWEN, 2006, p. 184).

Nesta articulação de sentidos no sistema, o elemento "Dado" na composição das imagens, posicionado à esquerda, é apresentado como algo conhecido, e portanto, familiar para o leitor. Já o conhecimento do "Novo" seria o inusitado e é apresentado como uma descoberta. Esse movimento de sentidos é muito particular a cada construção textualimagética, de modo que o próprio "Novo" pode, de modo conseguinte, apresentar-se como "Dado", seguindo-se outro elemento inesperado.

Por sua vez, a relação entre o "Ideal-Real" ressalta os elementos verticais da composição da imagem. Basicamente, esse valor informativo está relacionado ao fato de que, se há em uma imagem uma disposição de elementos no plano superior em relação ao plano inferior, os primeiros compõem, em geral, uma imagem "Ideal" do fenômeno em relação a uma imagem "Real", situada na parte inferior. Nesse sentido, os autores destacam que o "Ideal" é, em geral, posto como mais saliente, apresentando-se como objeto de desejo em relação à parte "Real", que representa o núcleo informativo.

Além disso, as imagens podem ser dispostas a partir da dimensão de centro e margem. E nesse sentido, a margem referese ao distanciamento em relação ao núcleo informativo. Ou seja, não necessariamente a margem da figura será marginal em relação ao núcleo informativo, de modo que pode haver nas margens uma centralização de informações. Segundo Kress e van Leeuwen (2006), em relação às margens, o que está localizado no centro "é apresentado como o núcleo da informação ao qual todos os outros elementos estão de alguma forma subordinados" (KRESS; VAN LEEUWEN, 2006, p. 25). 
Ainda sobre os elementos de composição textual, os autores destacam o princípio de framing. Este sistema está intimamente relacionado à disposição, isto é, ao enquadramento dos elementos da figura. Assim, o leitor conecta ou desconecta elementos da imagem em busca de um sentido. O princípio de framing, por sua vez, abrange a separação e/ou proximidade com que os elementos da imagem são dispostos em relação ao todo.

Já a saliência é definida, em linhas gerais, pela maneira de chamar a atenção do leitor para um segmento do texto através dos elementos que são dispostos para atrair a atenção do espectador em diferentes graus, realizando-se por meio de diferentes fatores (KRESS; VAN LEEUWEN, 2006). Ela envolve a disposição dos elementos no texto, pois é apresentada de acordo com o grau de importância das partes. Assim, pode ser que determinada parte do texto se encontre em maior evidência, ou completamente apagada em relação às demais. Vejamos nas palavras dos autores:

Mas a composição de uma imagem ou de uma página também envolve diferentes graus de saliência com relação aos seus elementos. Independentemente de onde estejam posicionados, a saliência pode criar uma hierarquia de importância entre os elementos, selecionando algum como o mais importante, como o merecedor de maior atenção que os demais. (KRESS; VAN LEEUWEN, 2006, p. 213)

Na composição visual, a revelação da saliência não obedece à hierarquia do Dado e Novo, Ideal e Real e à de Centro e Margem. Ao salientar um aspecto textual da composição, os autores alertam que o Dado pode ser mais saliente que o Novo, por exemplo, ou o Novo pode ser mais saliente que o Dado, ou ambos podem ser igualmente salientes.

Dessa forma, o critério de saliência envolve uma relação complexa entre os elementos textuais, uma vez que não é algo que pode ser mensurado objetivamente. Nessa articulação, a composição imagética fundamenta-se na relação de equilíbrio entre essas partes em um grau maior ou menor de saliência. Assim, cada elemento visual ocupa uma relação de sentido em relação aos demais, de modo a estabelecer um equilíbrio no plano integral da imagem.

Ainda no que tange ao critério da saliência na composição das imagens, Kress e van Leeuwen (2006) destacam que este sistema é julgado com base nas pistas visuais. Partindo-se da concepção de que os espectadores das composições visuais são intuitivamente capazes de julgar o "peso" dos vários elementos da composição, percebendo o destaque nas composições, quanto maior o peso, maior é a saliência. Passaremos, na seção seguinte, à metodologia que adotamos para este trabalho. 
v. 10 (esp) $50-65$ ago. 2020

\section{Metodologia}

Como já mencionado anteriormente, na composição dos textos multimodais, três são os sistemas responsáveis pela tessitura dos diferentes sentidos: o valor informativo, o framing e a saliência. Dentre eles, neste artigo é para a saliência que lançamos nosso olhar ao observarmos o gênero em questão.

Na busca por analisarmos como a saliência contribui para os efeitos de sentidos na composição do gênero anúncio publicitário, baseamo-nos nos pressupostos da pesquisa qualitativa de cunho descritivista (GIL, 2002). Para isso, partimos da observação de 10 anúncios publicitários que fazem parte da amostra selecionada durante a etapa da coleta do gênero analisado no projeto PIBIC/UERN ${ }^{1}$ 2018-2019 intitulado: "a argumentação nos anúncios publicitários - desvendando os caminhos da persuasão no gênero".

Como critério para a seleção desses anúncios em diferentes sites na internet, priorizamos os que, na composição de sentidos do gênero, apresentavam elementos em destaque que, na nossa concepção, atendessem melhor ao objetivo comunicativo do anunciante de promover o produto anunciado.

Nesse sentido, nossa pesquisa seguiu os seguintes passos metodológicos: 1) seleção e estudo da bibliografia que versa sobre o tema; 2) coleta e seleção do corpus constituído dos exemplares do gênero anúncio publicitário em diferentes sites de compra na internet; 3) observação e análise de como os elementos pertinentes à saliência, nos anúncios selecionados, articulavam-se para a construção de sentidos no gênero; 4) sistematização dos dados selecionados através da análise, partindo das três categorias que se destacaram na análise da saliência: o tamanho das imagens, o uso das cores e o destaque nas letras e, por fim, 5) planejamento e elaboração deste artigo.

É necessário salientar que o critério para a escolha dos três anúncios que melhor ilustram as reflexões provenientes de nossa análise para este artigo explica-se, principalmente, pelo fato de, durante a análise, terem sido os casos nos quais verificamos uma harmonia sistemática na combinação dos elementos imagéticos e verbais dos anúncios. Passaremos, em seguida, à discussão dos resultados das reflexões provenientes desta empreitada.

${ }^{1}$ Projeto aprovado no Edital Nº02/2017-PROPEG/UERN com ID número: 1563. 


\section{A análise e os resultados do estudo da saliência no anúncio publicitário}

$\mathrm{Na}$ tentativa de ilustrarmos alguns aspectos que se apresentaram importantes em nossa análise, selecionamos, para discutir nesta seção, três anúncios publicitários que representam as três categorias que se destacaram ao observarmos a saliência: 0 tamanho das imagens, o uso das cores e o destaque nas letras. Passaremos, então, ao anúncio representado na figura 1.

Saliência pelo tamanho das imagens

Figura 1 - Anúncio "LG gram"

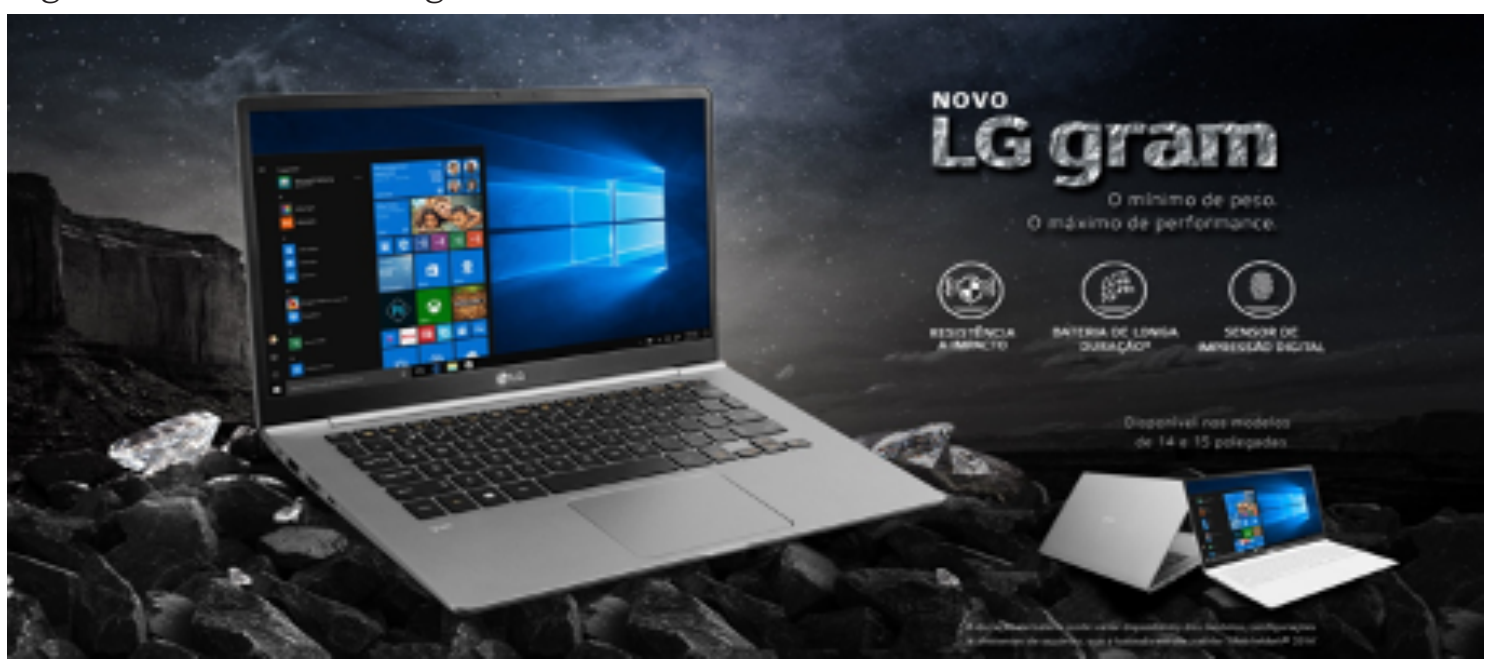

Fonte: Disponível em: https://www.lg.com/br/images/PC/features/hero-banner-v3. jpg. Acesso em: 02 mar. 2019.

O anúncio apresentado na figura 1 divulga os notebooks da linha "LG gram" e foi veiculado pela empresa "LG". Ao olharmos o anúncio, percebemos a saliência dada ao tamanho ampliado da imagem do notebook anunciado, posicionada do centro para o lado esquerdo do leitor, e colocada em primeiro plano, em relação à imagem de dois outros notebooks também presentes no anúncio à direita do leitor no anúncio. Isso contrasta, também, com o nome da marca, posicionado à direita do leitor, na parte superior do anúncio, associada à ideia de ser essa a marca ideal para esse tipo de eletrônico.

Outro aspecto da saliência está no contraste do tamanho destacado do notebook em relação ao tamanho reduzido da muralha, à esquerda, e às letras pequenas em tom de cinza claro, à direta, que representam a parte verbal do anúncio. Nela, o anunciante aponta algumas características atribuídas ao notebook: "o mínimo 
v. 10 (esp) $50-65$ ago. 2020

de peso", "o máximo de performance" e, ainda, "resistência a impacto", "bateria de longa duração" e "sensor de impressão". O contraste entre as letras pequenas nas expressões sobre as vantagens do notebook e o nome da linha de eletrônicos "LG gram" em maior tamanho e com as letras em tons de cinza semelhantes à aparência do diamante destaca-se bastante.

Os aspectos descritos acima reafirmam o que Kress e van Leeuwen (2006) defendem acerca da saliência não obedecer à hierarquia do Dado e Novo, Ideal e Real e à de Centro e Margem. Podemos perceber, nesse caso, que é notório o destaque dado ao notebook que foi posto mais à esquerda do que no centro, sendo essa posição, em geral, ocupada pelo elemento Dado e conhecido para o leitor, em detrimento aos demais elementos que compõem a imagem. Contudo, observamos que a imagem localizada nessa posição é justamente a do novo notebook da linha "LG gram".

Ainda no que tange ao anúncio da figura 1, a saliência revelase no tamanho aumentado de três pedras de diamantes do lado direito e do lado esquerdo com outros três diamantes bem menores ao redor do computador. Outro elemento da saliência, na composição de sentidos do anúncio, está no contraste do brilho dos diamantes, próximos ao notebook, em relação ao cinza escuro das rochas posicionadas na parte inferior do anúncio e que sustentam os notebooks anunciados, associando-os à ideia de durabilidade e de resistência. Passaremos, em seguida, ao segundo anúncio analisado.

Saliência através das cores

Figura 2 - Anúncio "Deva Curl"

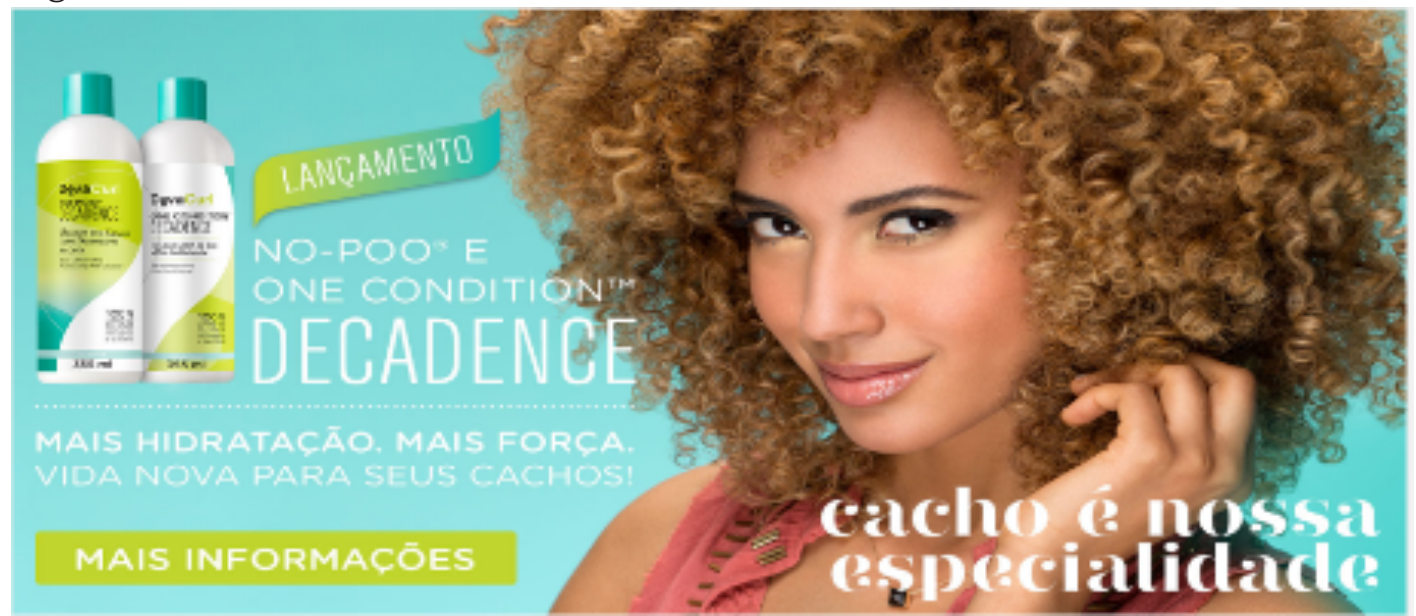

Fonte: Disponível em: https://devacurl.com.br/. Acesso em: 01 mar. 2019. 
O anúncio da figura 2, que pertence à empresa de cosméticos "Deva Curl", apresenta, à direita do leitor, a imagem de uma jovem mulher morena com os cabelos castanho-claros, ocupando todo o lado direito do anúncio. Nele, observamos que a saliência está presente em vários elementos usados na composição do anúncio, principalmente no jogo das cores.

Assim como no anúncio representado pela figura 1, novamente, o tamanho da imagem representa um forte elemento da saliência no anúncio, que se revela, também, no uso das cores no anúncio.

Nesse caso, o anunciante usa o branco e vários tons de verde que se articulam com as cores das embalagens do produto à direita. O castanho do cabelo cacheado da modelo contrasta com o fundo azul-esverdeado do anúncio, representando a informação nova. Esse aspecto ressalta o que Kress e van Leeuwen (2006, p. 185) defendem acerca da figura feminina possuir saliência cultural em qualquer contexto.

A cor do cabelo da modelo destaca-se, ainda, em relação ao branco das letras na mensagem: "CACHO É A NOSSA ESPECIALIDADE", articulando-se com o tom de pele da mulher e a cor rosa claro da blusa que ela usa.

O tom do azul-esverdeado ao fundo e do branco das letras remete às cores dos produtos anunciados, localizados à esquerda do leitor. A suavidade do azul-esverdeado e do branco contrasta com o tom do castanho-escuro dos olhos da modelo e com o tom do castanho-claro do cabelo dela.

$\mathrm{Na}$ imagem da mulher, o olhar provocante mirando em direção ao leitor e os fartos cabelos cacheados se sobressaem. O cabelo cacheado ganha destaque pelo volume avantajado, que contrasta com a impressão de leveza associada ao gesto do toque em alguns dos cachos. Em seguida, passaremos à análise do terceiro anúncio. 
V. 10 (esp) 50-65 ago. 2020

Saliência pelas letras

Figura 3 - Anúncio "Vanish"

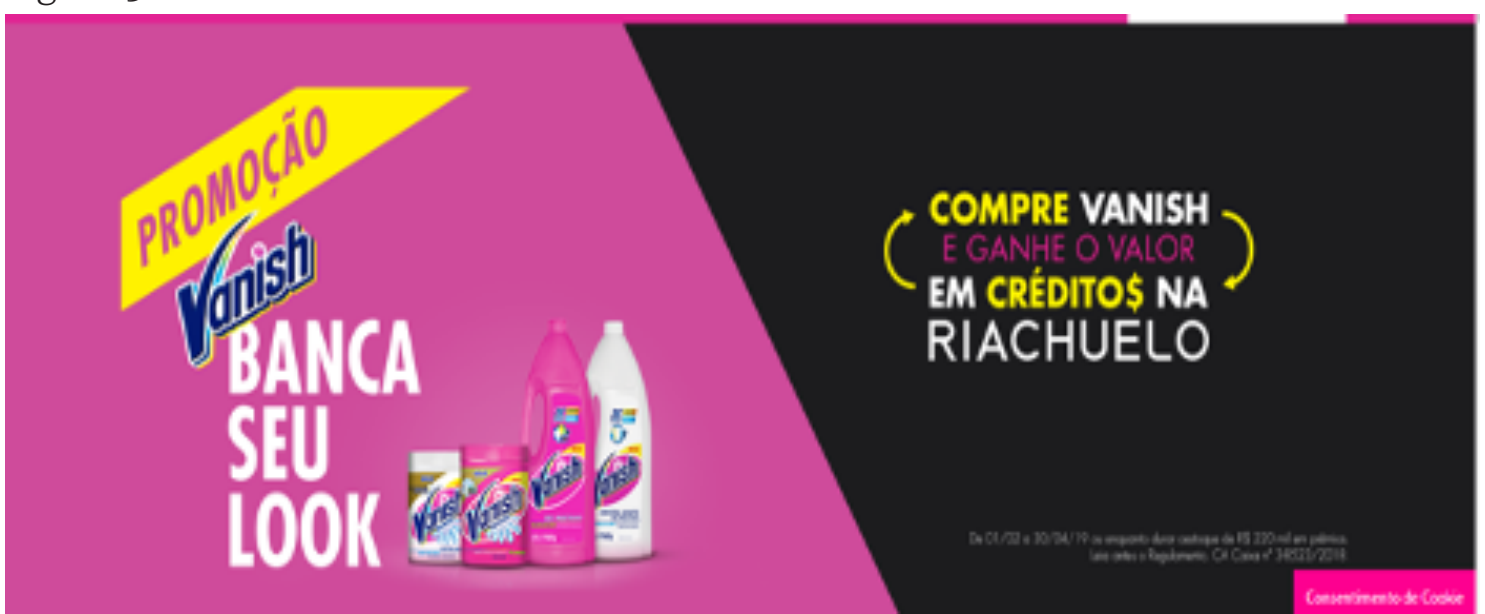

Disponível em: https://www.vanish.com.br/media/5147/miolo-banner-riachuelo. png. Acesso em: 18 mar. 2019.

O anúncio da marca "Vanish" tem o fundo dividido ao meio por uma linha transversal vertical, formando dois quadriláteros: um rosa, à esquerda do leitor, e outro preto, à direita.

Percebemos que, além do destaque pelas cores do fundo do anúncio, a saliência revela-se no tamanho, nos tipos e nas diferentes cores usadas nas letras que trazem a linguagem verbal.

Ao analisarmos as letras apresentadas no anúncio da figura 3, observamos que, na parte superior à esquerda, um quadrilátero amarelo traz a palavra "PROMOÇÃO" em letras maiúsculas, em itálico e no mesmo tom de rosa do fundo. A cor amarela da figura geométrica combina com o amarelo dos termos "COMPRE" e "CRÉDITOS". Logo abaixo, aparece o nome da marca "Vanish" em letras azuis e em formato igual ao nome da logomarca no rótulo das embalagens dos produtos que aparecem no anúncio.

Nessa composição de sentidos no gênero, podemos perceber que a saliência se dá, também, pela estratégia do anunciante de usar, nas cores das letras presentes na linguagem verbal do anúncio, as mesmas cores das embalagens dos produtos da marca, apresentados na base inferior do fundo rosa do anúncio.

As imagens dos produtos nas cores rosa e branco combinam com o rosa das letras utilizadas na palavra "PROMOÇÃO" em itálico acima do nome da marca "BANCA SEU LOOK", que aparece em letras brancas. 
O destaque dado ao tamanho das letras brancas, dispostas ao lado dos produtos, na passagem: "BANCA SEU LOOK", remete à ideia do branco como resultado dos alvejantes da marca. Esse recurso, juntamente com a saliência da palavra promoção no quadrilátero amarelo, corrobora o que defendem Kress e van Leeuwen (2006) a respeito do fato de que "a saliência pode criar uma hierarquia de importância entre os elementos, selecionando algum como o mais importante, como o merecedor de maior atenção que os demais." (KRESS; VAN LEEUWEN, 2006, p. 213).

A saliência evidenciada pelo contraste nas cores usadas na linguagem verbal do anúncio acontece nos dois lados. No fundo preto à direita do leitor, o anúncio novamente apresenta essa estratégia. O contraste nas cores: amarelo, branco e rosa nas letras maiúsculas das palavras presentes na passagem: "COMPRE VANISH E GANHE O VALOR EM CRÉDITOS NA RIACHUELO" e o jogo de alternação destas cores nas palavras dão maior saliência à mensagem.

Nessa última passagem comentada, outro elemento que dá destaque às letras das palavras interagindo com elas são duas setas amarelas curvadas. Essas setas são posicionadas uma do lado esquerdo da mensagem e outra do lado direito. Elas associam as sequências: "COMPRE VANISH" e "EM CRÉDITOS NA RIACHUELO", dando mais saliência à informação.

É importante mencionar que, na última sequência: "EM CRÉDITOS NA RIACHUELO", o anúncio traz a saliência na articulação do símbolo do cifrão substituindo o "s" na palavra "créditos". Esse símbolo articula-se com o nome da loja "Riachuelo" que aparece destacado em letras brancas maiores do que as outras letras usadas no resto da mensagem. A associação do cifrão à ideia de valores, a articulação com o nome da loja "Riachuelo" e a mensagem: "Vanish BANCA SEU LOOK" reforçam os objetivos comunicativos do anunciante na divulgação dos produtos da marca. A saliência revela-se, também, no uso do branco na cor das letras usadas no nome "Riachuelo", no branco das embalagens dos produtos "Vanish" e no trecho: "Vanish BANCA SEU LOOK".

Diante do exposto, é inegável a articulação da linguagem verbal com os elementos imagéticos no que tange à análise da saliência. 
v. 10 (esp) 50-65 ago. 2020

\section{Considerações finais}

Observamos que a saliência está presente em vários elementos usados na composição visual dos anúncios analisados e assume posição relevante na tessitura de sentidos do gênero observado. Nesse sentido, alguns pontos importantes merecem comentário.

Na articulação dos recursos que compõem o gênero anúncio, a manipulação do tamanho das imagens e o contraste ocasionado por essa manipulação de tamanhos representaram um forte aspecto da saliência no gênero, atuando conforme os propósitos comunicativos dos anunciantes.

Para revelar a saliência, o anunciante vale-se também do uso das cores (em diferentes tons) na composição do anúncio. Dessa forma, pudemos constatar a predominância de cores pesadas, como o cinza, sugerindo requinte, durabilidade e resistência (no caso do anúncio representado pela figura 1 ) e, ainda, o branco e o tom claro do azulesverdeado sugerindo a ideia de leveza, como ocorreu no caso da figura que representa o anúncio 2.

O tamanho e o jogo de cores nas letras também são responsáveis por revelar a saliência nos anúncios, como no caso do anúncio 3. Nele, o anunciante usa as letras em tamanho maior e o contraste delas com a cor do fundo para salientar a mensagem de associação do slogan da promoção com a loja mencionada, proporcionando uma articulação entre o verbal e o imagético.

Outros dois aspectos merecem comentário por reafirmarem o que defendem Kress e van Leeuwen (2006). O primeiro é o fato de a saliência da figura feminina destacar-se e, ainda, o pressuposto de que saliência não obedece à hierarquia do Dado e Novo, Ideal e Real e à de Centro e Margem, como foi constatado na articulação dos elementos imagéticos dos anúncios analisados.

Diante do que foi exposto, constatamos o quanto pode ser relevante uma análise dos anúncios com base nas questões que envolvem a saliência e como esse sistema atua na tentativa de persuadir o consumidor a adquirir os produtos anunciados.

Agradecimentos: Ao apoio concedido pelo PIBIC/UERN para o desenvolvimento do projeto que motivou este artigo. 


\section{Referências}

GIL, Antônio Carlos. Como elaborar projeto de pesquisa. 4. ed. São Paulo: Editora S.A, 2002.

HALLIDAY, Michael Alexander Kirkwood. An introduction to functional grammar. 2. ed. London: Edward Arnold, 1994.

HALLIDAY, Michael Alexander Kirkwood; MATTHIESSEN, Christian Mathias Ingemar Martin. An introduction to functional grammar. 3. ed. London: Hodder Education, 2004.

KRESS, Gunther; VAN LEEUWEN, Theo. The meaning of composition. In: KRESS, Gunther; VAN LEEUWEN, Theo. Reading images: the grammar of visual design. London: Routledge, 2006. p. 174-214.

MOTTA-ROTH, Déssiré; HEBERLE, Viviane. O conceito de "estrutura potencial do gênero" de Ruqayia Hasan. In: MEURER, José Luis; BONINI, Adair; MOTTAROTH, Déssiré (orgs.). Gêneros, teorias, métodos, debates. 1. ed. São Paulo: Parábola Editorial, 2005.

PETERMANN, Juliana. Imagens na publicidade: significações e persuasão. UNIrevista, vol. 1, n. 3, 2006. Disponível em: https://www.iar.unicamp.br/ lab/luz/ld/Linguagem\%20Visual/imagens_na_publicidade. Acesso em: 03 jun. 2019. 